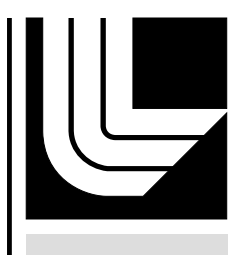

LAW RENCE LIVERMORE NATIO N A L LABORATORY

\title{
UCRL-TR-218465
}

\section{Seismicity and Improved Velocity Structure in Kuwait}

R. M. Gok, A. J. Rodgers, A. Al-Enezi

January 27, 2006 
This document was prepared as an account of work sponsored by an agency of the United States Government. Neither the United States Government nor the University of California nor any of their employees, makes any warranty, express or implied, or assumes any legal liability or responsibility for the accuracy, completeness, or usefulness of any information, apparatus, product, or process disclosed, or represents that its use would not infringe privately owned rights. Reference herein to any specific commercial product, process, or service by trade name, trademark, manufacturer, or otherwise, does not necessarily constitute or imply its endorsement, recommendation, or favoring by the United States Government or the University of California. The views and opinions of authors expressed herein do not necessarily state or reflect those of the United States Government or the University of California, and shall not be used for advertising or product endorsement purposes.

This work was performed under the auspices of the U.S. Department of Energy by University of California, Lawrence Livermore National Laboratory under Contract W-7405-Eng-48. 


\title{
Seismicity and Improved Velocity Structure in Kuwait
}

\author{
Rengin Gok ${ }^{1}$, Arthur Rodgers ${ }^{1}$ and Abdullah Al-Enezi ${ }^{2}$ \\ ${ }^{1}$ Atmospheric, Earth and Energy Department \\ Lawrence Livermore National Laboratory Livermore,CA, 94551 USA \\ ${ }^{2}$ Environment and Urban Development Division \\ Kuwait Institute for Scientific Research, Safat, Kuwait \\ Report to the Kuwait Institute for Scientific Research \\ January 25, 2006
}




\section{Summary}

The Kuwait National Seismic Network (KNSN) began operation in 1997 and consists of nine three-component stations (eight short-period and one broadband) and is operated by the Kuwait Institute for Scientific Research. Although the region is largely believed to be aseismic, considerable local seismicity is recorded by KNSN. Seismic events in Kuwait are clustered in two main groups, one in the south and another in the north. The KNSN station distribution is able to capture the southern cluster within the footprint of the network but the northern cluster is poorly covered. Events tend to occur at depths ranging from the free surface to about $20 \mathrm{~km}$. Events in the northern cluster tend to be deeper than those in south, however this might be an artifact of the station coverage.

We analyzed KNSN recordings of nearly 200 local events to improve understanding of seismic events and crustal structure in Kuwait, performing several analyses with increasing complexity. First, we obtained an optimized one-dimensional (1D) velocity model for the entire region using the reported KNSN arrival times and routine locations. The resulting model is consistent with a recently obtained model from the joint inversion of receiver functions and surface wave group velocities. Crustal structure is capped by the thick $(\sim 7 \mathrm{~km})$ sedimentary rocks of the Arabian Platform underlain by normal velocities for stable continental crust. Our new model has a crustal thickness of $44 \mathrm{~km}$, constrained by an independent study of receiver functions and surface wave group velocities by Pasyanos et al (2006). Locations and depths of events after relocation with the new model are broadly consistent with those reported by KISR, although a few events move more than a few kilometers. We then used a double-difference tomography technique (tomoDD) to jointly locate the events and estimate three-dimensional (3D) velocity structure. TomoDD is based on hypoDD relocation algorithm and it makes use of both absolute and relative arrival times. We obtained $\sim 1500$ absolute $\mathrm{P}$ and $\mathrm{S}$ arrival times and $\sim 3200 \mathrm{P}$ and $\mathrm{S}$ wave arrival time differences. Event locations do not change greatly when $3 \mathrm{D}$ velocity structure is included. Three-dimensional velocity structure, where resolvable, does not differ greatly from our optimized 1D model, indicating that the improved 1D model is adequate for routine event location. Finally, we calculated 
moment magnitudes, $M_{W}$, for nearly 155 events using the coda magnitude technique of Mayeda et al., (2003).

The fact that most of the relocated events occur below the known sedimentary structures extending to $7 \mathrm{~km}$ suggests that they are tectonic in origin. Shallow events within the sedimentary crust in the (southern) Minagish region may be related to oil field activities, although the current study cannot unambiguously determine the source of current seismicity in Kuwait. The improved velocity model reduces the scatter of travel time residuals relative to the locations reported in the KNSN bulletin and may be used for ground motion prediction and hazard estimate studies in Kuwait.

\section{Introduction}

Kuwait is located in the northeastern part of the Arabian Peninsula at the northwestern end of the Arabian Gulf. Active tectonics in the area is largely dominated by the collision along the Zagros Fold Belt some 200-300 km to the east (Figure 1). The convergence zone and erosion due to the uplift of mountains caused uplift and a thick sedimentary cover ( 7-10km) (Laske \& Masters 1997; Pasyanos et al., 2005). Kuwait lies at the edge of Arabian foreland where the northeast dipping monocline passes into the geosyncline of the Arabian Gulf and Mesopotamian Foredeep. The interaction of the Arabian and Zagros folds is apparent in the submarine topography of the Arabian Gulf, as well as in the subsurface structures of Kuwait. The topography of Kuwait is controlled by the intense folding of the Zagros orogeny in a northwest to southeast trend. The quaternary sediments show evidence for continuation of the uplifting movements that formed the large anticlines of the Great Burgan Oil Field and other oil fields in Kuwait during Cretaceous.

The Kuwait Institute for Scientific Research (KISR) deployed Kuwait National Seismic Network (KNSN) in 1997. This digital real-time seismic network consists of 7 threecomponent short-period and 1 broadband seismic stations. The seismic data are digitized using 24-bit digitizers with a sampling rate of 100 samples/sec (Bau-Rabee, 2000). The 
KNSN detects and locates local, regional and teleseismic events. An event bulletin is generated by the KNSN. Between the period of March 1997 and November 2004175 local events were recorded and located by KNSN.

\section{Reference 1-D Velocity Model}

One of the main functions of a seismic network is to produce a bulletin of event hypocenters (location and depth) and magnitudes. The accuracy of the bulletin depends on the accuracy of the seismic velocity model used to determine the hypocenters. Because geologic structure varies greatly in the crust due to tectonic processes, crustal seismic velocities can vary greatly. Thus it is necessary to obtain a region-specific seismic velocity model in order to obtain the most accurate hypocenters. Other factors that impact the accuracy of earthquake location process are the data quality and the accuracy of analyst arrival times (picks). To investigate the accuracy of reported arrivals we re-picked most of the arrivals and compared with the KNSN-reported picks. In general we found the KNSN arrival times were accurate, however, we were able to include more $\mathrm{P}$ - and S-wave arrivals for emergent or signal/noise arrivals after trying different filters.

We used the available bulletin hypocenters and arrival times to obtain an improved seismic velocity model for Kuwait. We were fortunate to have independent estimates of crustal structure from a recent study by Pasyanos et al. (2006). This study obtained a model of crustal and uppermost mantle velocities from a joint inversion of receiver functions and surface group velocities. The improved model was obtained by simultaneous solving for the hypocenters and velocity model, using a computer program called VELEST (Kissling et al. 1995b). This algorithm finds the combination of event hypocenters and velocity model that is consistent with the P-and S-wave arrival times at the recording stations. The search for a minimum 1D model starts with a trial-and-error process using a wide range of realistic and possibly unrealistic starting velocity models. Unrealistically high or low velocities were used as well to define the entire range of possible acceptable solutions. The goal of this procedure is to first define the range of 
possible solutions and second to find the most appropriate solution for the posed problem (Figure 2). The resolution of velocity model is poorly defined for upper and lower crust due to the coverage of ray paths connecting events and stations. We investigated a wide range of starting models and performed several tests before obtaining the final inversion results. We found that the velocity model is robustly determined in the depth range 8-20 $\mathrm{km}$. Because the available rays paths provide poor coverage of the upper and lowermost crust, we fixed the uppermost $(0-5 \mathrm{~km})$ crustal structure and crustal thickness using model of Pasyanos et al., (2006). We used the crustal thickness of $44 \mathrm{~km}$ from the same inversion results.

The initial KNSN relocated epicenters are shown in Figure 3. Figure 3b shows the initial and relocated epicenters, along with the ray path coverage. We do not observe a major shift in hypocenters after relocating with the improved velocity model (Figure 3b). The clustering of events is mostly concentrated in the north and the south. We obtain about $75 \%$ variance reduction of rms residuals. The new $1 \mathrm{D}$ velocity model for Kuwait is a major improvement to existing velocity model. It can be used for different purposes such as locations or as a reference model to the $3 \mathrm{D}$ inversion.

Another technique for improving phase picks is to apply a waveform cross-correlation. If the waveforms for closely located events are very highly correlated with each other, their waveform similarity is used to adjust the picks and improve the event locations by clustering. We used a Matlab tool (Matseis) and Rowe et al., (2001)'s automatic pick adjustment technique to calculate the cross correlation and waveform similarity. We do observe a few very highly correlated events. However, there were not enough events that to successfully apply this technique.

\section{Three-dimensional P-wave Velocity Structure}

Using the improved 1D velocity model for Kuwait, we then investigated 3D velocity structure, using travel time tomography. Results of local earthquake tomography depend strongly on the initial reference model (Kissling et al. 1994). An appropriate initial 
model for local earthquake tomography should be close to the true 1D average model. Recent studies have shown substantial improvement in location precision and accuracy for earthquakes and explosions when event-clustering techniques are used to improve arrival time estimates or determine high-precision relative arrival times (Waldhauser and Ellsworth, 2000). The double-difference tomography technique, hypoDD and tomoDD (Zhang and Thurber, 2003) use both the differential and absolute arrival time of the data to estimate locations and 3D seismic velocity structure. It is known that there is a coupling effect between the event hypocenters and the velocity structure (Thurber, 1992). Our purpose is to determine not only the relative event locations, but also their absolute locations and the velocity structure. The advantage in using a double difference technique is to eliminate the overlapping path effects common to nearby events traveling to a single station. As a result the model derivatives will essentially cancel outside the source region, helping to isolate the relative locations of the events. Besides using the double differences of nearly earthquakes, the absolute arrival times are used in the inversion to resolve the velocity structure outside the source region. By doing this, we can simultaneously determine the velocity structure and the relative event locations as well as the absolute event locations in an accurate fashion.

We obtained $\sim 1500$ absolute $\mathrm{P}$ and $\mathrm{S}$ arrival times and $\sim 3200 \mathrm{P}$ and $\mathrm{S}$ wave arrival time differences recorded at 8 stations. TomoDD uses the pseudo-bending raytracing algorithm (Um and Thurber, 1987) to find the rays and calculate the travel times between events and stations. The model is represented as a regular set of 3D nodes, and the velocity values are interpolated by using the trilinear interpolation method. The hypocentral partial derivatives are calculated from the direction of the ray and the local velocity at the source. The ray path is divided into a set of segments, and the model partial derivatives calculated in terms of fractional slowness perturbation (Thurber, 1983). We used $20 \times 20 \mathrm{~km}$ grid spacing in xy direction and $1-10 \mathrm{~km}$ at the vertical.

The resulting 3D P-wave velocity structure is shown in Figure 5. A major low velocity anomaly seen in central western Kuwait (Figure 4, Profile 5). This region is poorly sampled by the available ray paths (Figure $3 \mathrm{~b}$ ) and the model is poorly resolved in this 
area. We hope that additional data may be able to sample this feature and determine if it is real or an artifact of the tomographic inversion. The model shows some 3D structure, but is broadly consistent with the average 1D structure described in the previous section. In the northern part of the model, the upper layers $(0-10 \mathrm{~km})$ tend to have lower velocities than the average 1D model. This may reflect differences in sedimentary structure.

\section{Coda Magnitudes}

Studies on local coda waves suggest that coda waves are the result of weak scattering from small-scale heterogeneities within the Earth's crust. Taking advantage of the averaging nature of coda waves, Mayeda et al. (2003) developed a completely empirical method providing stable earthquake moment-rate spectra, which can be used to derive seismic moments, $\mathrm{M}_{0}$, and moment magnitudes, $\mathrm{M}_{\mathrm{W}}$, at both local and regional distances. Mayeda et al. (2003) describes the method more in-depth. For each event the two horizontal components of ground motion are used to obtain narrowband envelopes for a set of discrete frequency bands in a range $0.5-8.0 \mathrm{~Hz}$. Then synthetic envelopes are fit to the observed data yielding dimensionless coda amplitudes at a range of frequencies. (Figure 5)

Mayeda et al (2003), allows for a distance-dependent effect to account for different coda envelope behavior at local and regional distances. Consequently to remove path effects we used the following functional form,

$$
P(r, f)=\left[1+\left(\frac{r}{p_{2}}\right)^{p_{1}}\right]^{-1}
$$

where $r$ is the distance and $f$ is the frequency. The above form depends on two parameters, the roll-off $\left(p_{1}\right)$ and cross-over distance $\left(p_{2}\right)$. These parameters were derived for the region using a grid-search technique. 
Finally, the distance corrected amplitudes are tied to an absolute scale using independent moment estimates (Figure 6) determined from long-period waveform modeling for the low frequencies, and an empirical Green's function correction for the higher frequencies. These corrections account for the S-to-coda transfer function as well as the site response. We also compared distance-corrected coda and direct wave amplitude residuals as a function of distance and from Figure 6. We conclude that there are no biases in the corrected coda amplitudes, validating our path corrections. When we tie our distancecorrected coda amplitudes to an absolute scale using indepently derived moments from waveform modeling (Figure 7) the dimensionless coda amplitude spectra transform into an absolute moment-rate spectra (Figure 8). For events with multiple station recordings we observed that very similar coda-derived source spectra are obtained for different stations (Figure 6). This confirms that we properly calibrated path and site/transfer correction parameters obtaining high precision measurements.

Finally, we compared the KNSN local magnitudes, $\mathrm{M}_{\mathrm{L}}$, with the coda envelope $\mathrm{M}_{\mathrm{W}}$ 's. We observe a large scatter in local magnitudes with respect to moment magnitude (Figure 9a). In general, $M_{W}$ scales with $M_{L}$ with the ratio of $2 / 3$ as expected (Hanks and Kanamori, 1979). When we compare moment-rate spectra for events of similar size in Kuwait with known tectonic events on the Northern Anatolian Fault in Turkey we see good agreement (Figure 9b).

\section{Conclusion}

Using the arrival time data of KNSN we obtained improved event locations and a new 1D seismic velocity model. The model obtained from travel time analysis complements the model obtained from inversion of receiver function and surface wave group velocities (Pasyanos, et al., 2006). The simultaneous inversion for event hypocenters and 1D velocity structure is able to resolve structure in the depth range between $8-20 \mathrm{~km}$. The preliminary tomographic inversion results for $3 \mathrm{D}$ velocity structure indicate some resolvable deviations from 1D structure. In the northern part of Kuwait, there appears to be lower velocities near the surface than the 1D suggests. A large low velocity feature in 
the western part of Kuwait does not have enough path coverage to be resolved. There may be a small feature that might be smeared and seen as a large feature in the 3D model.

The relocated hypocenters are slightly different than the routine locations reported by the KNSN. Events in the north of Kuwait tend to be deeper (8-25) than those in the south (0$25 \mathrm{~km}$ ). The fact that most of the relocated events occur below the known sedimentary structures extending to $7 \mathrm{~km}$ suggests that they are tectonic in origin, occurring in the crystalline crust. Shallow events within the sedimentary crust in the (southern) Minagish region may be related to oil field activities, although the current study cannot unambiguously determine the source of current seismicity in Kuwait. The improved velocity model reduces the scatter of travel time residuals relative to the locations reported in the KNSN bulletin and may be used for ground motion prediction and hazard estimate studies in Kuwait. Comparison of magnitudes for the available events show high scatter between KNSN reported local magnitudes, $\mathrm{M}_{\mathrm{L}}$, and coda $\mathrm{M}_{\mathrm{W}}$. However, it scales approximately $2 / 3$ as expected. The source spectra of events show close similarity between the tectonic events from other regions such as the North Anatolian Fault Zone (Figure 9b). The seismicity of Kuwait can be still related to the hydrocarbon removal even though most events occur below the sedimentary structure of the shallow upper crust and have moment-rate spectra similar to other tectonic events. It is possible that the events were caused by changes in stress induced by the hydrocarbon removal, but the current study cannot not unambiguously resolve this issue.

\section{References}

Bou-Rabee, F., 2000, Seismotectonics and earthquake activity of Kuwait, J. Seism., 4, 133-141.

Hanks, T. and H. Kanamori, (1979), A moment-magnitude scale, J. Geophys. Res., Volume 84, Issue B5, p. 2348-2350

Kissling, E., W.L. Ellsworth, D. Eberhart-Phillips, and U. Kradolfer, (1994) Initial reference models in local earthquake tomography, J. Geophys. Res., 99, 19635-19646 
Mayeda K., A Hofstetter, JL O'Boyle, and WR Walter, (2003), A stable transportable coda magnitudes based on coda-derived moment-rate spectra, Bull. Seis. Soc. Am., 93, 224-239.

Pasyanos M.E., (2005), A variable resolution surface wave dispersion study of Eurasia, North Africa, and surrounding regions, J. Geophys. Res.,, Vol 110 (B12): No. B12301.

Pasyanos ME, Tkalcic H., A.J. Rodgers, and A. Al-Enezi, (2006), Seismic structure of Kuwait: A case study of improvements to structural estimates from the installation of a broadband station, in press

Rowe C., R. C. Aster, B. Borchers and C. J. Young, An Automatic, (2002), Adaptive Algorithm for Refining Phase Picks in Large Seismic Data Sets, Bull. Seis. Soc. Am., Vol. 92; no. 5, p. 1660-1674

Um J., and C. Thurber, (1987) A fast algorithm for two-point seismic ray-tracing, Bull. Seis. Soc. Am., Vol. 77, no. 3, p. 972-986

Waldhauser F. and W. Ellsworth, (2000), A Double-Difference Earthquake Location Algorithm: Method and Application to the Northern Hayward Fault, California, Bull. Seis. Soc. Am., Vol. 90: 1353-1368.

Zhang H. and C. Thurber, Double-Difference Tomography, (2003). Double-difference tomography: A method and its application to the Hayward Fault, Bull. Seis. Soc. Am., Vol. 93, 1875-1889.

\section{Figure Captions}

Figure 1 The tectonic setting of Kuwait and surrounding regions. Seismicity for the period 1972-1998 are shown (red circles) taken from the ISC catalog. The circle size is proportional to the event magnitude. 
Figure 2. P-wave velocity results for Kuwait. a) Shaded area is the depth range where we can resolve velocities $(8-20 \mathrm{~km})$ Dotted gray lines are output of various input models). The velocities between $8-20 \mathrm{~km}$ is resolvable. The yellow line is the final model we obtained through the inversion.b) The velocity model obtained through the joint inversion of receiver functions and surface wave group velocities.

Figure 3. a) The main structural features of Kuwait are dominated by large, oil producing anticlines (shaded areas). Seismicity (green dots) is shown with green circles b) The relocated epicenters (red) did not shift significantly from the original locations. The dept range is between $0-20 \mathrm{~km}$ and it concentrated in two different locations.

Figure 4. Three-dimensional (3D) P-wave velocity structure for Kuwait, derived from the tomoDD double-difference tomography method. The structure (bottom) is shown for the series of cross-sections, 1-7, form the map (top).

Figure 5 An example of observed coda wave envelopes (black) fit with synthetic envelopes (red) at station MIB.

Figure 6 Inter-station variation for direct waves are about 3.5 times larger than coda waves. Based on the spatial residuals, a 1-D model for coda is perfectly adequate.

Figure 7 The long-period waveform modeling result of December 30, 1997 Managish earthquake. This was the largest event recorded by the KNSN. The long-period waveforms were modeled at the broadband station KBD to yield an $\mathrm{M}_{\mathrm{W}}$ of 4.2.

Figure 8 Absolute source spectra of the 155 earthquakes. The largest event recorded was at Managish with $\mathrm{Mw}=4.2$ and the smallest $\mathrm{Mw}=1.8$.

Figure 9 a) The scaling between ML and Mw b) The comparison of tectonic events from North Anatlolian Fault Zone and Kuwaiti events. 


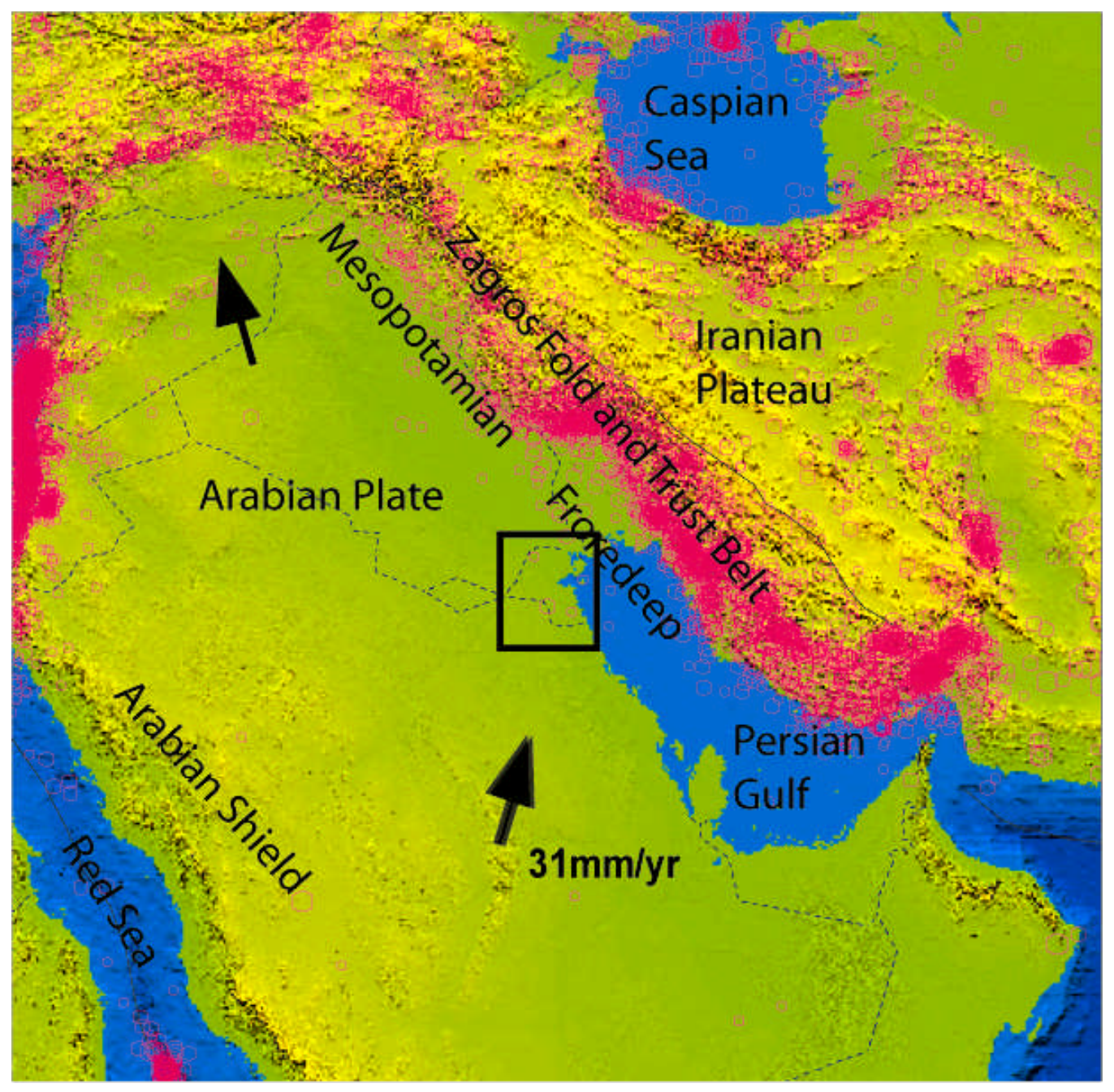

Figure 1. 
a)

\section{Model}
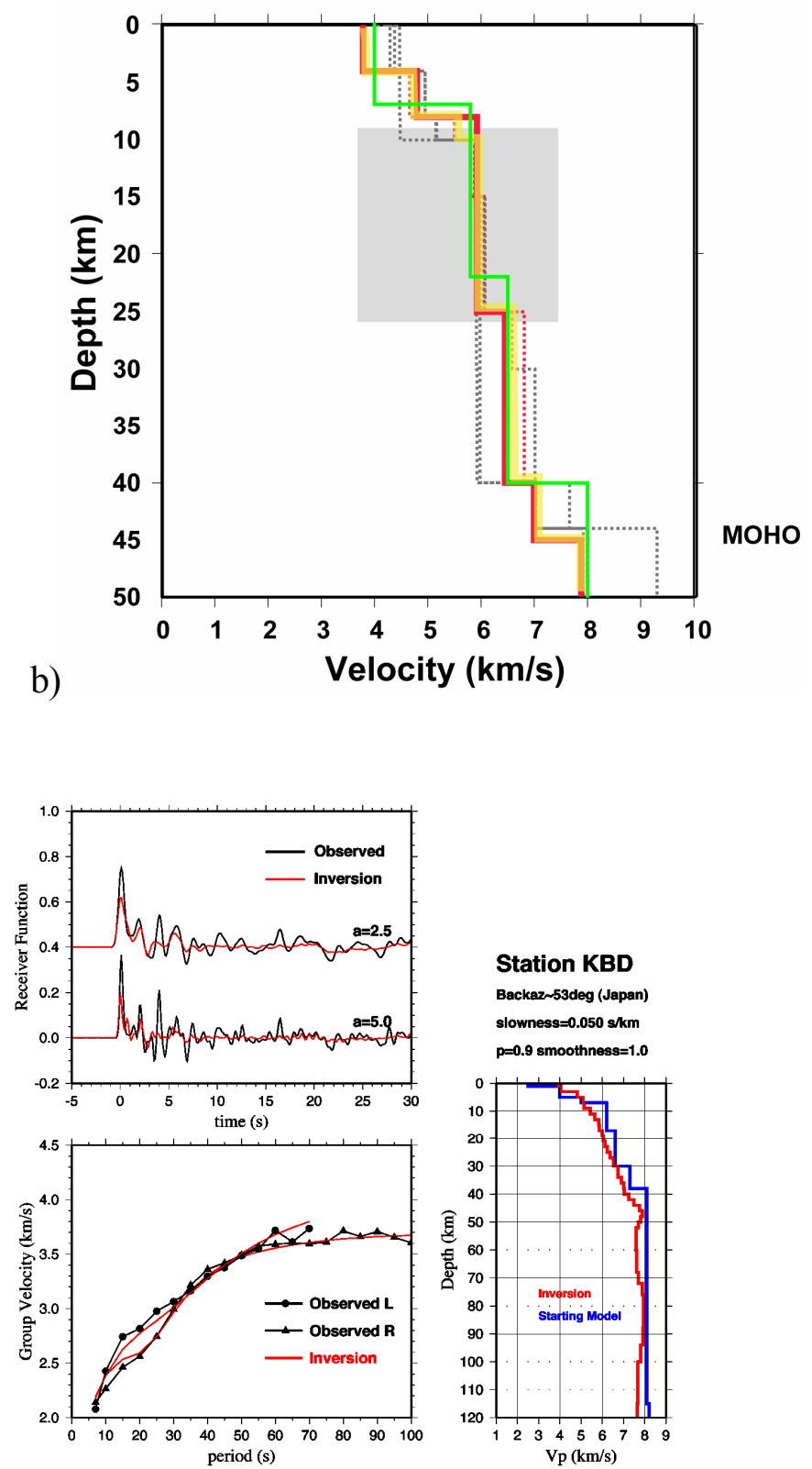

Figure 2 

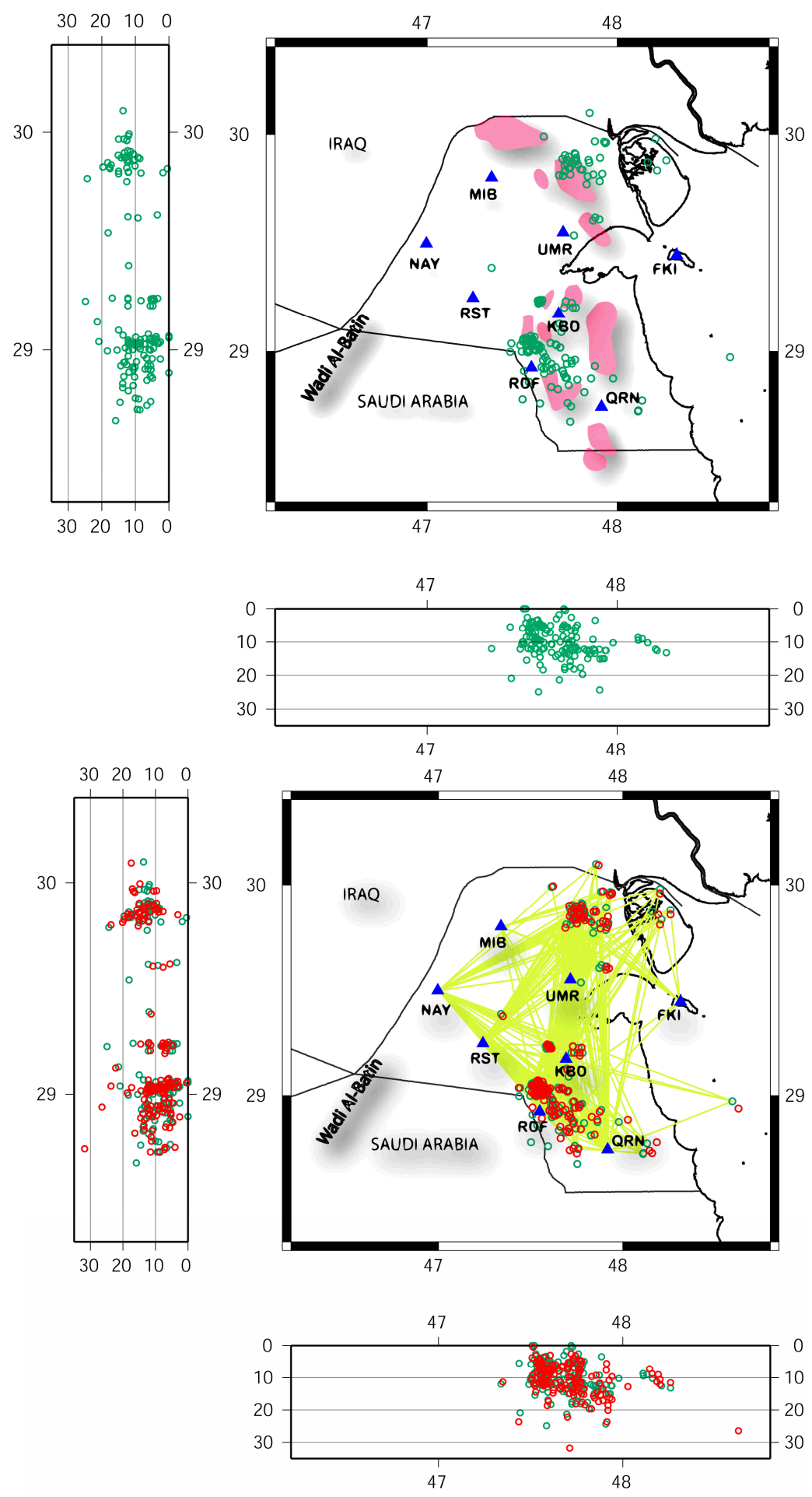

Figure 3. 

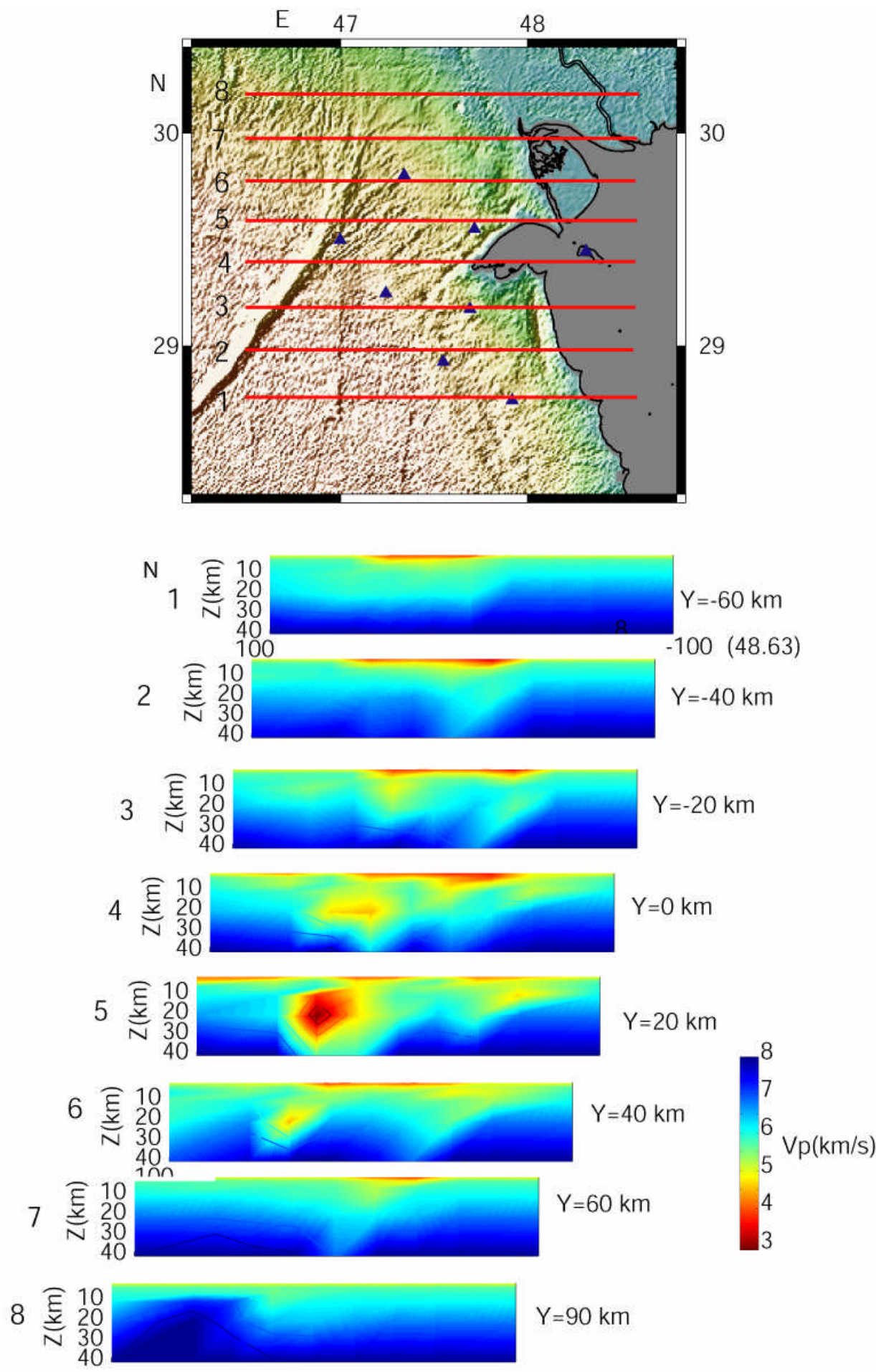

Figure 4. 


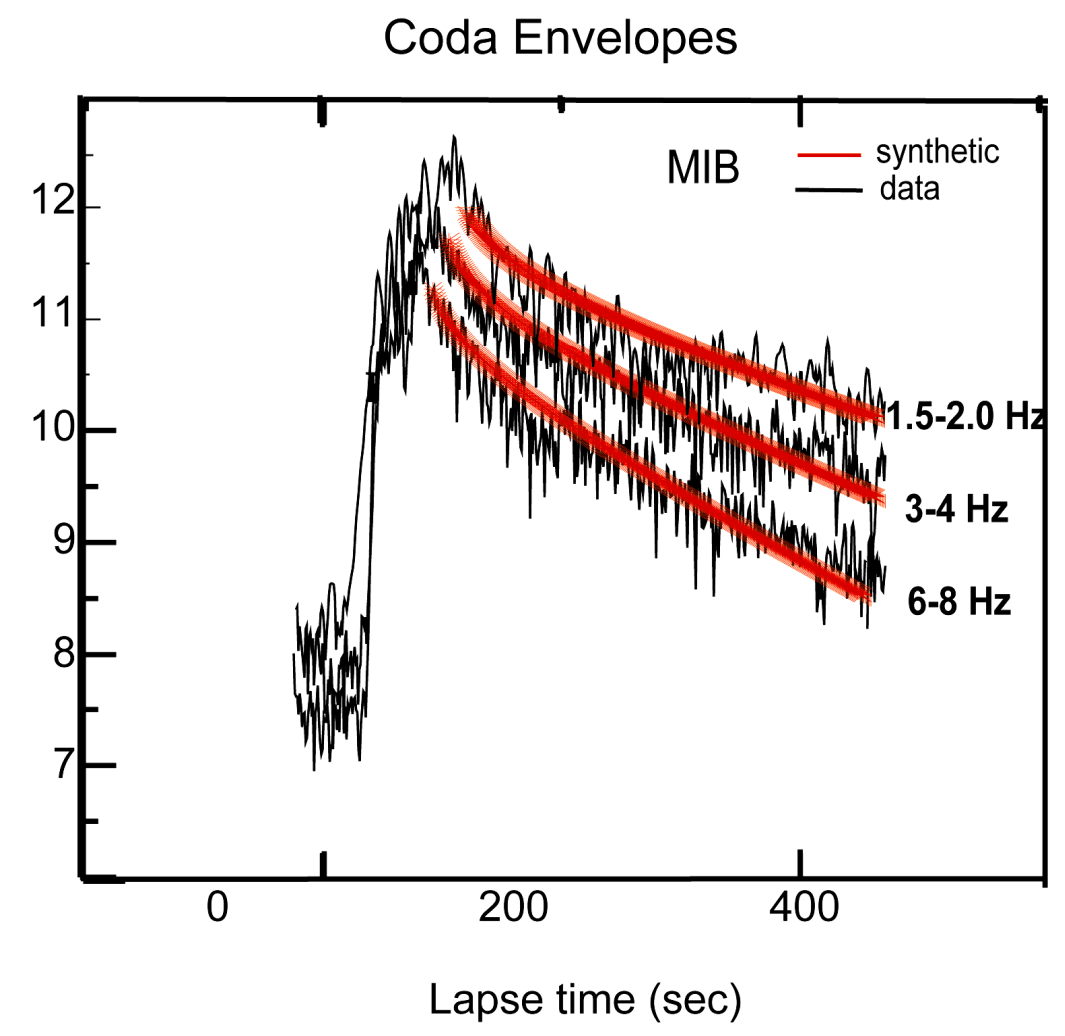

Figure 5 
KBD-NAY 2.0-3.0 Hz
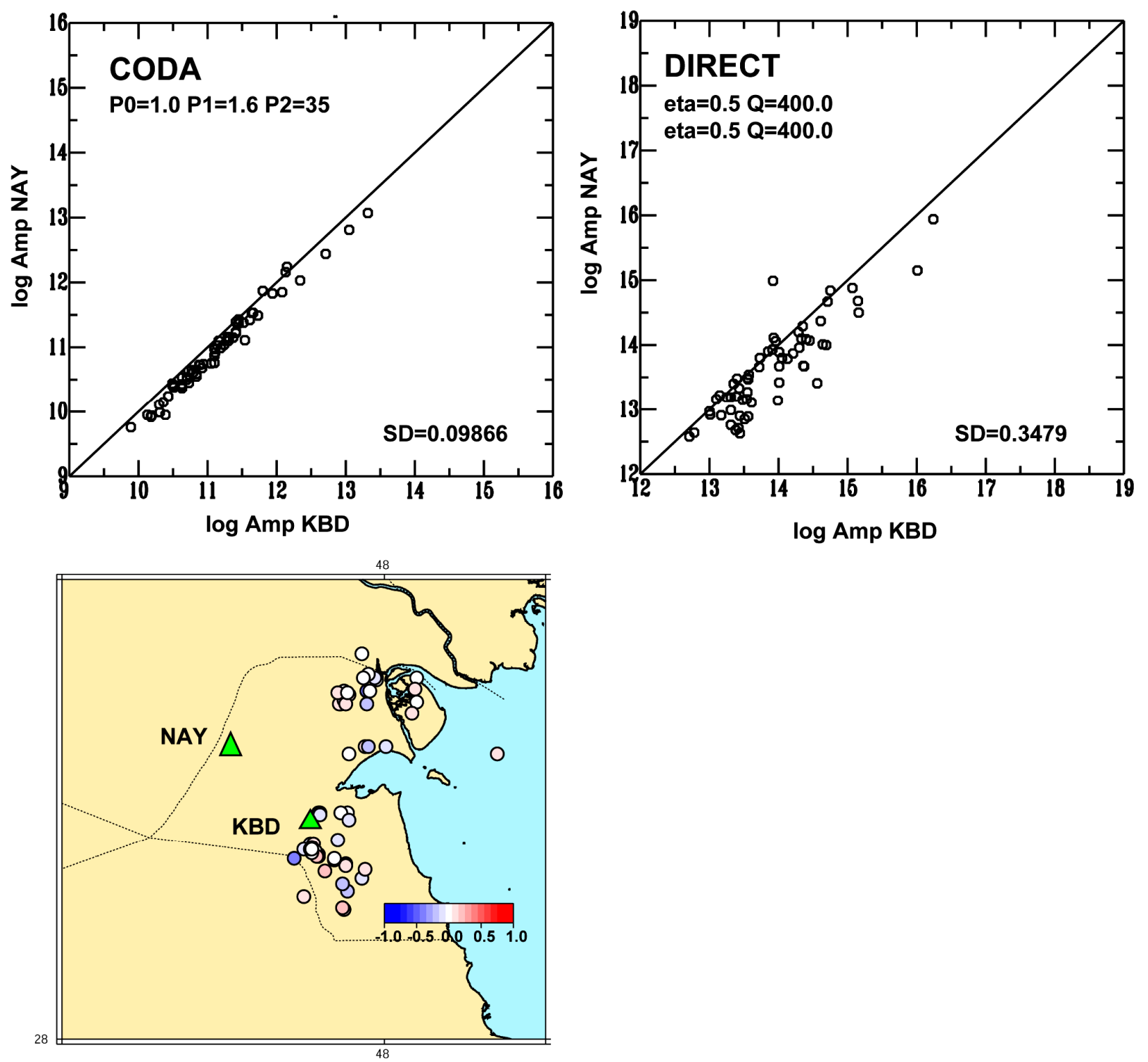

Figure 6 
Long-Period Waveform Modeling

Managish Earthquake (Mw=4.2)

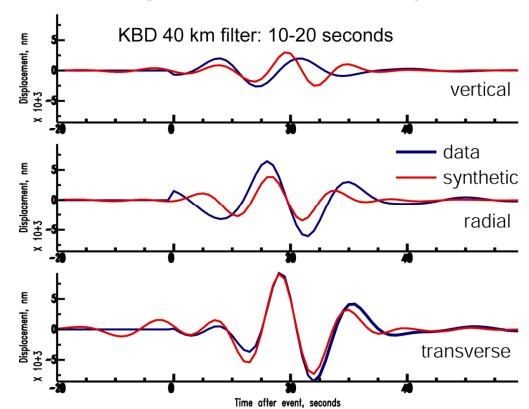

Depth-Mechanism-Misfit Curve

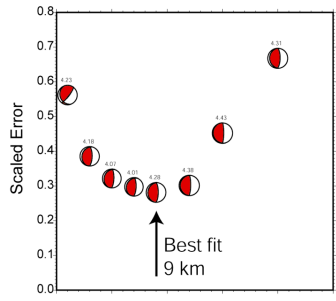

Figure 7
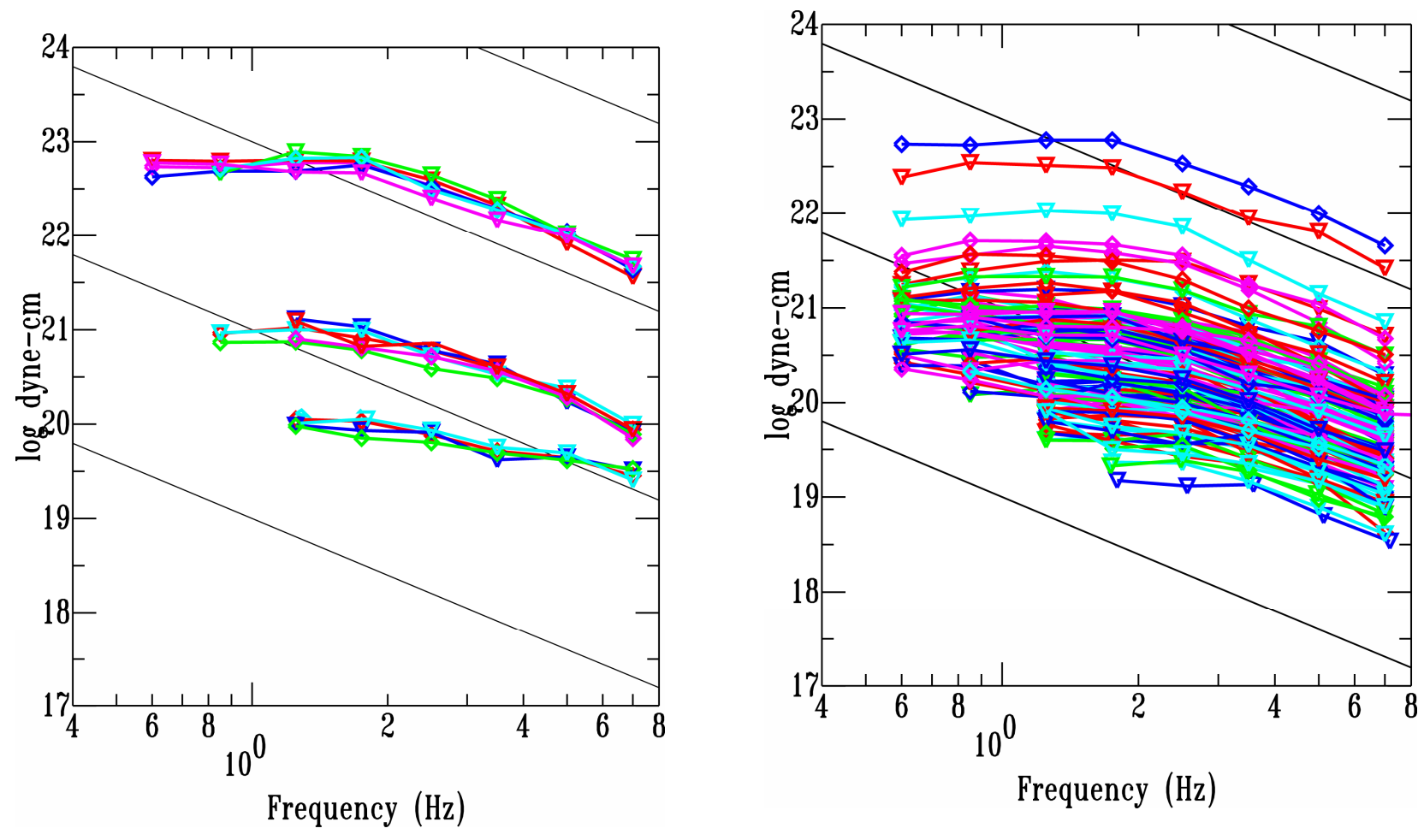

Figure 8 
a)

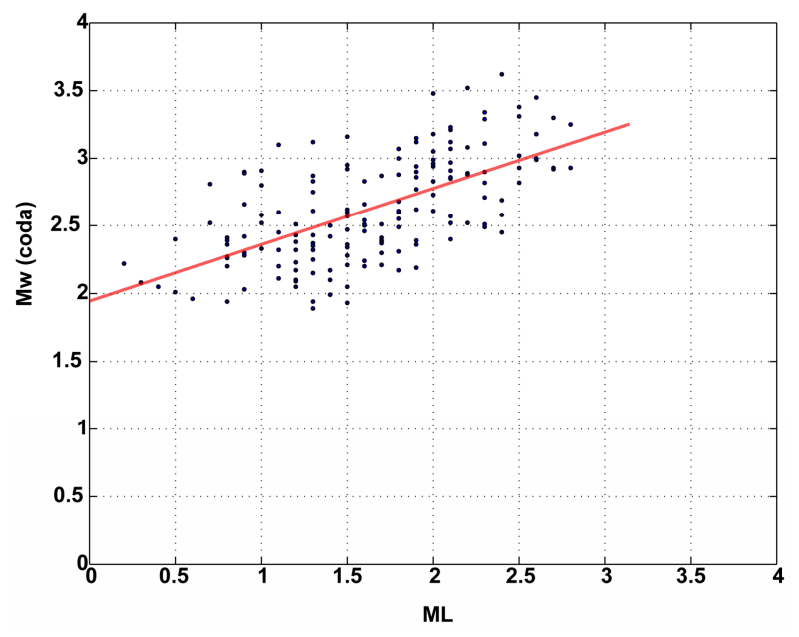

b)

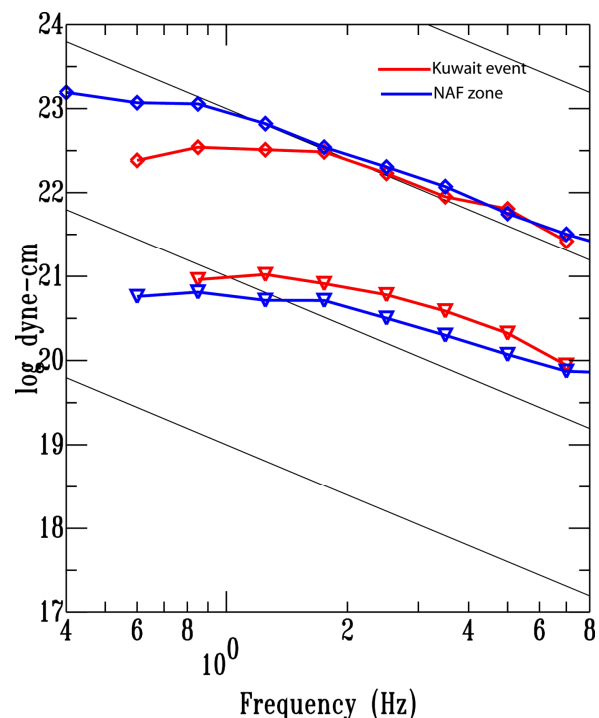

Figure 9 